\title{
Genetic variants in the distal enhancer region of the PSA gene and their implication in the occurrence of advanced prostate cancer
}

\author{
SUSHANT V. CHAVAN ${ }^{1}$, ANURUPA MAITRA ${ }^{2}$, NOBHOJIT ROY $^{3}$, SUJATA PATWARDHAN $^{4}$, PADMA R. CHAVAN $^{5}$ \\ ${ }^{1}$ Department of Biochemistry, Lokmanya Tilak Municipal Medical College; ${ }^{2}$ Department of Molecular Endocrinology, \\ National Institute for Research in Reproductive Health; ${ }^{3}$ Department of Surgery, BARC Hospital; \\ ${ }^{4}$ Department of Urology, Seth Gordhandas Sunderdas Medical College and King Edward Memorial Hospital; \\ ${ }^{5}$ Department of Biochemistry, Topiwala National Medical College and BYL Nair Charitable Hospital, Mumbai, India
}

Received February 24, 2010; Accepted June 28, 2010

DOI: $10.3892 / \mathrm{mmr} .2010 .341$

\begin{abstract}
The identification of men predisposed to advanced prostate cancer is important as it influences diagnostic and treatment modalities. In this study, we examined variants in the prostate specific antigen (PSA) gene and their possible association with the risk of prostate cancer, the occurrence of advanced disease, and serum PSA levels. Three functional single nucleotide polymorphisms (SNPs) in the enhancer region of the PSA gene, -5429T/G, -5412T/C and -4643A/G, were genotyped in 84 prostate cancer cases and 109 controls using the SNaPshotTM multiplex technique. Prostate cancer patients were divided into two groups: those with localized $(n=37)$ and advanced $(n=36)$ disease. Between these two groups, two SNPs, -5429T/G and -5412T/C, were found to have statistically significant differences in PSA genotype frequencies. The heterozygous genotype in the PSA gene conferred an increased risk of advanced prostate cancer. After age-adjustment, the estimated OR and 95\% CI for $-5429 \mathrm{~T} / \mathrm{G}$ and $-5412 \mathrm{~T} / \mathrm{C}$ was 3.59 (1.16-11.09; $\mathrm{P}<0.02)$, and 3.26 (1.04-10.22; $\mathrm{P}<0.02)$, respectively, whereas for $-4643 \mathrm{~A} / \mathrm{G}$, the OR was $2.46(0.86-$ 7.04; $\mathrm{P}<0.08)$. The haplotype $-5429 \mathrm{G} /-5412 \mathrm{C} /-4643 \mathrm{G}$ with $11 \%$ frequency conferred a 3.5 -fold increased risk of advanced prostate cancer $(95 \% \mathrm{CI}=1.02-11.76 ; \mathrm{P}<0.051)$. Genotype distribution between the controls and prostate cancer cases did not demonstrate a statistically significant difference $(\mathrm{P}>0.05)$. Genotype-based serum PSA levels for each SNP were also observed to be similar ( $P>0.05$ ). Heterozygosity observed in the PSA gene enhancer region contributes substantially to the occurrence of advanced prostate cancer. The identification of men at risk for advanced disease by PSA genotype may aid in determining the most effective therapeutic strategy, with the aim of improving the quality of life of patients.
\end{abstract}

Correspondence to: Dr Padma R. Chavan, Department of Biochemistry, Topiwala National Medical College and BYL Nair Charitable Hospital, A.L. Nair Road, Mumbai 400 008, India E-mail: padmachavan@rediffmail.com

Key words: prostate cancer, advanced prostate cancer, distal enhancer region, prostate specific antigen gene

\section{Introduction}

The risk of prostate cancer development varies widely worldwide. African-Americans are at the highest risk followed by Caucasians, while Asians are the least affected $(1,2)$. In India, the incidence of prostate cancer is low compared to western countries. The average annual prostate cancer incidence rate in India is in the range of 5.0-9.1/100,000, whereas comparative rates in the US for prostate cancer are 110.4 for whites and 180.9 for blacks (3).

The detection of prostate cancer in Indian men is based on symptomatic presentation. The treatment regimen is determined based on the identification of localized or advanced (metastatic) disease. In patients diagnosed with advanced prostate cancer, metastasis to the bone confers a high risk of morbidity and mortality.

Serum prostate specific antigen (PSA), a serine protease secreted by prostate epithelial cells, has hitherto been employed for the diagnosis and determination of prognosis of prostate cancer. However, the PSA test is fraught with false positive or negative findings, which affects its diagnostic efficacy towards prostate cancer detection $(4,5)$. Moreover, the PSA test lacks the ability to predict the metastatic status of prostate cancer (6).

The identification of a novel biomarker for prostate cancer is currently the subject of intense investigation. The genetic variants that predispose men to advanced disease are being studied with the aim of facilitating screening, diagnosis and the determination of treatment. Examining the key genetic variants in the PSA gene and its association with disease aggression may lead to improvements in the identification of men predisposed to advanced prostate cancer.

PSA gene expression is largely under androgenic control via the androgen receptors. To date, three androgen response elements (AREs) have been reported in the PSA gene: ARE I and II in the proximal promoter region (7), and ARE III in the far upstream enhancer region (8). Several single nucleotide polymorphisms in this gene and their possible association with the risk of prostate cancer and serum PSA levels have been studied. Until recently, the single nucleotide polymorphism (SNP) at $-158 \mathrm{G} / \mathrm{A}$ has been the most studied polymorphism of the PSA gene, but no consensus about its significance in 
Table I. Primers used for PCR amplification.

SNP

rs256733, rs 2739448

rs925013
Sequence (5'-3')

PCR products

$350 \mathrm{bp}$

$370 \mathrm{bp}$
F: TGCAACCTTGGCTCACTGC

R: CAACCATGAAGACAGTCAACATGTC

F: CTAGACCAGGGACACTCTGGATG

R: TACTGACAAACAGGTGGGCAC prostate cancer has been reached thus far (9-22). Cramer et al reported a possible association between SNPs in the enhancer region of the PSA gene and serum PSA levels (22). In vitro functional analysis of polymorphisms at -5429 $\mathrm{T} / \mathrm{G}$ (rs2569733), -5412 T/C (rs2739448) and -4643 A/G (rs925013) showed a significant influence on PSA promoter activity (22).

With this as our basis, we explored a possible association between the polymorphisms exhibited by the enhancer region of the PSA gene and the risk of prostate cancer, the occurrence of advanced disease, and the levels of serum PSA in Indian men.

\section{Material and methods}

Study subjects. The study included 84 male patients with clinically and histologically diagnosed prostate cancer and 109 age-matched normal healthy male controls. Recruitment of patients was prospective as well as retrospective. Histologically proven cases of prostate cancer were included irrespective of the clinical stage of disease. The detailed clinical findings of prostate cancer cases, including baseline serum PSA levels, DRE examination, ultrasonography findings, Gleason score, bone scan findings and clinical staging, were noted following a thorough review of the medical records. Controls were selected after thorough evaluation of prostate abnormalities based on voiding symptoms as defined by the American Urological Association (AUA). Selected cases had an AUA score of $<8$ and serum PSA levels of $<4 \mathrm{ng} / \mathrm{ml}$. Subjects with a history of lower urinary tract infection symptoms were excluded. Written informed consent was obtained from all participants. The research protocol for the study was approved by the Institutional Review Board (IRB).

Advanced prostate cancer. Based on clinical staging, the prostate cancer patients were divided into two groups: those with localized and those with advanced disease. The advanced disease group exhibited invasion and extension of the malignancy beyond the capsule and/or to the adjacent tissue or involving regional lymph nodes (stage III) or distant metastasis sites (stage IV). In the localized disease group, the malignancy was confined to the prostate (stages I and II). Clinical staging (I-IV) was performed according to the TNM system. Among the 84 prostate cancer cases, clinical staging including bone scan findings was available in 73 cases. Upon further examination of these 73, advanced disease was found in 36 cases, while localized disease was observed in 37 . Bone metastasis was observed in 35 of the advanced prostate cancer cases.
Polymorphisms. Three functional SNPs in the far upstream enhancer region of the PSA gene were selected for evaluation: $-5429 \mathrm{~T} / \mathrm{G}$ (rs2569733), -5412 T/C (rs2739448) and -4643 A/G (rs925013).

DNA extraction and PCR amplification of the PSA gene for genotype analysis. Peripheral blood samples were collected for genotype analysis and the estimation of serum PSA levels by ELISA. For genotype analysis, DNA was obtained from the blood samples using a DNA extraction kit (Qiagen, USA). Two DNA segments in the enhancer region of the PSA gene encompassing the three SNPs were amplified by PCR, with one segment having two SNPs (rs 2569733 and rs 2739448) and the other having one (rs925013). The primers used for PCR amplification are presented in Table I. PCR was carried out in a $25 \mu \mathrm{l}$ reaction volume with $40 \mathrm{ng}$ of genomic DNA, $10 \mathrm{pmol} /$ $\mu \mathrm{l}$ of primers (Sigma-Aldrich), $10 \mathrm{mmol}$ dNTP, $1.5 \mathrm{mM} \mathrm{MgCl}$ and $1 \mathrm{U}$ of Taq polymerase (Fermentas). PCR cycling conditions were identical for both the amplification reactions except for the annealing temperature. Initial denaturation was at $95^{\circ} \mathrm{C}$ for $5 \mathrm{~min}$ followed by 35 cycles at $95^{\circ} \mathrm{C}$ for $1 \mathrm{~min}$, annealing at $64.5^{\circ} \mathrm{C}$ for rs 2569733 and rs 2739448 and at $63.5^{\circ} \mathrm{C}$ for rs 925013 for $1 \mathrm{~min}$, and then extension at $72^{\circ} \mathrm{C}$ for $1 \mathrm{~min}$, with a final elongation step at $72^{\circ} \mathrm{C}$ for $10 \mathrm{~min}$. The PCR products obtained were further checked for quality and yield on $1.5 \%$ agarose gel.

Multiplex SNaPshot reaction. The SNaPshot multiplex reaction was a multiplexed single base extension reaction that simultaneously analyzes all three SNPs in the PSA gene with specifically designed primers of varying sizes complementary to the template of interest.

Primer design. The oligonucleotide primers for the SnaPshot reaction were designed with the help of primer express software (Applied Biosystems, Foster City, USA). Each primer was designed with a different length of poly(dT) tail to allow separation of SNaPshot products based on size. Primers (Sigma-Aldrich) designed for the SNaPshot reaction are presented in Table II.

Standardization. A SNaPshot primer focus kit (P/N 4329538, Applied Biosystems Foster City, USA) was used to analyze individual primers for their approximate sizing locations prior to performing the SNP genotyping multiplex reactions. This procedure examines whether or not two oligonucleotides will produce overlapping signals when run simultaneously, and enables the setting of tight loci windows for GeneMapper 4.0 analysis software. 
Table II. Primers used for the SNaPshot multiplex reaction.

\begin{tabular}{ll}
\hline SNP & \multicolumn{1}{c}{ Sequence $\left(5^{\prime}-3^{\prime}\right)$} \\
\hline rs 256733 & F: TTTTTTTTTTTGGCCTCCCAAAGTGCTGGGAT \\
rs2739448 & R: TTTTTTTTTTTTTAATCTCTGGATATCGGCCAGGCGC \\
rs925013 & F: TTTTTTTTTTTTTTTTTCTCTTTCTGACCTCCACCATG
\end{tabular}

Table III. Clinical characteristics of the prostate cancer patients and controls.

\begin{tabular}{lcc}
\hline Characteristics & Cases $(\mathrm{n}=84)$ & Controls $(\mathrm{n}=109)$ \\
\hline Age (mean \pm SD) & $67.4 \pm 7.9$ & $68 \pm 7.4$ \\
Serum PSA (ng/ml) (mean \pm SD) & $150.7 \pm 404.05$ & $1.45 \pm 0.61$ \\
Gleason Score & & - \\
Low (<7) & $18(22 \%)$ & - \\
Intermediate (7) & $28(33 \%)$ & - \\
High (>7) & $38(45 \%)$ & - \\
Clinical staging (n=73) & $37(51 \%)$ & - \\
Localized (stages I and II) & $36(49 \%)$ \\
Advanced (stages III and IV) & 35 \\
Bone metastasis & \\
\hline
\end{tabular}

SNP analysis. An ABI PRISM SNaPshot multiplex kit from Applied Biosystems was used for SNP analysis. The two amplified PCR products of the PSA gene were pooled together at a ratio of 1:2 (100 ng for rs2569733 and rs2739448 and $50 \mathrm{ng}$ for rs925013. Pooled PCR products $(5 \mu \mathrm{l})$ were treated with $2 \mu \mathrm{l}$ of Exo-SAP IT (USB Corp.) to remove primer-dimer contamination and were further used for a SNaPshot multiplex reaction. The reaction included $5 \mu \mathrm{l}$ ready reaction mix, $3 \mu \mathrm{l}$ pooled PCR product, $1 \mu \mathrm{l}$ pooled SNaPshot primers and $1 \mu \mathrm{l}$ deionized water. The thermal cycling conditions were 25 cycles at $96^{\circ} \mathrm{C}$ for $10 \mathrm{sec}, 50^{\circ} \mathrm{C}$ for $5 \mathrm{sec}$ and $60^{\circ} \mathrm{C}$ for $30 \mathrm{sec}$. In this reaction, the primers anneal to their respective templates and the SNaPshot reaction extends each primer by the addition of a single fluorescently labeled dideoxyribonucleoside triphosphate over the SNP site. The SNaPshot reaction product was further cleaned with Exo-SAP IT for $1 \mathrm{~h}$ at $37^{\circ} \mathrm{C}$, followed by heat inactivation at $72^{\circ} \mathrm{C}$ for $15 \mathrm{~min}$. The reaction product was run on an ABI PRISM 3100 DNA sequencer using the GeneScan $^{\mathrm{TM}} 120$ LIZ $^{\circledR}$ Size Standard. Sequenced samples with known PSA genotype were used as the positive control during each run. Data obtained were analyzed using GeneMapper analysis software version 4.0 (Applied Biosystems).

Statistical analysis. The two groups, controls and prostate cancer patients, were sub-grouped according to genotype. Serum PSA levels were log-transformed and analyzed for differences between the two genotypes for each SNP using the unpaired t-test. All three SNPs in the control group were checked for Hardy Weinberg equilibrium. Analysis of the genotype data was performed using SNPStats statistical software (http://bioinfo.iconologia.net/snpstats) made available in the public domain by the Biostatistics and Bioinformatics Unit of the Catalan Institute for Oncology (Barcelona, Spain). The $\chi^{2}$ test was used to analyze differences in the genotype frequencies between the patients and the control group. After age-adjustment, the odds ratio and $95 \%$ CI were determined to predict disease susceptibility for specific genotypes in the PSA gene. Lewontin's D' statistics were calculated to estimate the strength of linkage disequilibrium (LD) between all possible pairwise combinations of SNPs, with $\mathrm{D}^{\prime}<0.25$ indicating low, 0.25-0.49 mild, 0.5-0.74 moderate and 0.75-1.0 strong LD. In addition, a test for global and individual PSA haplotype association with prostate cancer was performed with SNPstat software. P-values $<0.05$ were considered statistically significant.

\section{Results}

Subject characteristics. The detailed characteristics of the prostate cancer patients and controls are presented in Table III. The age of the prostate cancer patients and that of the normal healthy male controls did not differ significantly. The average serum PSA levels observed in the controls and prostate cancer cases were $1.45 \mathrm{ng} / \mathrm{ml}$ and $150.7 \mathrm{ng} / \mathrm{ml}$, respectively. Wide variability in serum PSA levels, ranging from $0.15 \mathrm{ng} / \mathrm{ml}$ to $3318 \mathrm{ng} /$ $\mathrm{ml}$, was observed at the time of prostate cancer diagnosis. The Gleason score pattern observed was $\geq 7$ in $78 \%$ of the prostate cancer cases. Clinical staging was available in 73 prostate cancer cases and revealed advanced prostate cancer in 36 cases and 37 cases with localized malignancy. Bone metastasis was observed in 35 of the 36 cases of advanced prostate cancer. 
Table IV. Association between genotype frequencies of SNPs in the PSA gene enhancer region and prostate cancer risk.

\begin{tabular}{|c|c|c|c|c|c|}
\hline SNP & Variants & $\begin{array}{c}\text { Controls }(\mathrm{n}=109) \\
\mathrm{n}(\%)\end{array}$ & $\begin{array}{c}\text { Cases }(\mathrm{n}=84) \\
\mathrm{n}(\%)\end{array}$ & OR $(95 \% \mathrm{CI})^{\mathrm{a}}$ & P-value \\
\hline \multirow[t]{2}{*}{ rs256733 (-5429 T/G) } & $\mathrm{TT}$ & $79(72.5)$ & $60(71.4)$ & 1.00 & \\
\hline & TG & $30(27.5)$ & $24(28.6)$ & $1.05(0.56-1.98)$ & 0.87 \\
\hline \multirow[t]{2}{*}{ rs2739448 (-5412 T/C) } & $\mathrm{TT}$ & $79(72.5)$ & $61(72.6)$ & 1.00 & \\
\hline & $\mathrm{TC}$ & $30(27.5)$ & $23(27.4)$ & $0.99(0.52-1.88)$ & 0.98 \\
\hline \multirow[t]{2}{*}{ rs925013 (-4643 A/G) } & AA & $77(70.6)$ & $59(70.2)$ & 1.00 & \\
\hline & $\mathrm{AG}$ & $32(29.4)$ & $25(29.8)$ & $1.02(0.55-1.90)$ & 0.95 \\
\hline
\end{tabular}

${ }^{\mathrm{a} A g e}$-adjusted odds ratio.

Table V. Association between the PSA genotype in the enhancer region and the occurrence of advanced prostate cancer.

\begin{tabular}{lccccr}
\hline SNP & Variants & $\begin{array}{c}\text { Localized (n=37) } \\
\mathrm{n}(\%)\end{array}$ & $\begin{array}{c}\text { Advanced (n=36) } \\
\mathrm{n}(\%)\end{array}$ & OR (95\% CI) & P-value \\
\hline rs256733 (-5429 T/G) & TT & $31(83.8)$ & $22(61.1)$ & 1.00 & \\
& TG & $6(16.2)$ & $14(38.9)$ & $3.59(1.16-11.09)$ & 0.021 \\
rs2739448 (-5412 T/C) & TT & $31(83.8)$ & $23(63.9)$ & 1.00 & \\
& TC & $6(16.2)$ & $13(36.1)$ & $3.26(1.04-10.22)$ & 0.021 \\
rs925013 (-4643 A/G) & AA & $29(78.4)$ & $22(61.1)$ & 1.00 & 0.086 \\
& AG & $8(21.6)$ & $14(38.9)$ & $2.46(0.86-7.04)$ & 0.040 \\
\hline
\end{tabular}

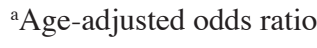

Association of genotype frequencies with prostate cancer risk. The genotype frequencies of all three SNPs (rs2569733, rs2739448 and rs925013) in the prostate cancer and control groups are presented in Table IV. Two genotypes were observed for each SNP prevalent in the population. The major homozygous genotypes, TT for rs2569733, TT for rs2739448 and AA for rs925013, were prevalent in $70-73 \%$ of the subjects, whereas heterozygous genotypes were prevalent in $27-30 \%$ of subjects. The minor homozygous genotype could not be demonstrated in our study population. The genotype distribution observed for the controls was in perfect Hardy Weinberg equilibrium $(\mathrm{P}>0.1)$. After age-adjustment of all three SNPs of the PSA gene, no statistically significant difference between the genotype frequencies of the prostate cancer cases and controls was observed, indicating no association with the risk of prostate cancer $(\mathrm{P}>0.1)$.

Association of PSA genotype frequencies with the risk of advanced prostate cancer. With respect to clinical stage, the distribution of PSA genotype adjusted by age showed a statistically significant difference between localized and advanced prostate cancer for the SNPs rs2569733 and rs2739448, whereas rs925013 showed marginal significance. The genotype frequencies of rs 2569733 , rs 2739448 and rs925013 in the localized and advanced prostate cancer cases are presented in Table V. After age adjustment, a significantly increased risk of advanced prostate cancer was demonstrated for men with the heterozygous genotype for $\mathrm{rs} 2569733(\mathrm{OR}=3.59 ; 95 \% \mathrm{CI}$ 1.16-11.09), rs2739448 (OR=3.26; 95\% CI 1.04-10.22) and rs925013 (OR=2.46; 95\% CI 0.86-7.04).

Association of the PSA haplotype with prostate cancer and advanced prostate cancer. Significant pairwise linkage disequilibrium was observed between all three SNPs $(\mathrm{P}<0.001)$ with pairwise $\mathrm{D}^{\prime}$ estimates of $0.97,0.86$ and 0.86 for the pairings $(-5429,-5412),(-5429,-4643)$ and $(-5412,-4643)$, respectively. The haplotypes $-5429 \mathrm{~T} /-5412 \mathrm{~T} /-4643 \mathrm{~A}$ and $-5429 \mathrm{G} /-5412 \mathrm{C} /-4643 \mathrm{G}$ appeared as major haplotypes in the study population (Tables VI and VII).

No statistically significant difference in the PSA haplotype frequencies was observed between the controls and prostate cancer cases $(P>0.05)$. However, a marginally significant difference in haplotype frequency was demonstrated between localized and advanced prostate cancer cases after age adjustment (Table VI). As shown in Table VII, a 3.46-fold increased risk of advanced prostate cancer was found to be associated with the haplotype $-5429 \mathrm{G} /-5412 \mathrm{C} /-4643 \mathrm{G}$, with a frequency of $11 \%$. However, the global haplotype effect on advanced prostate cancer risk was non-significant $(\mathrm{P}<0.18)$.

PSA genotype and serum PSA levels. Table VIII presents the log transformed mean \pm SD of serum PSA levels stratified according to PSA genotype for the controls and prostate cancer cases. No significant difference in PSA levels was 
Table VI. Association between PSA haplotype frequencies and prostate cancer risk.

\begin{tabular}{lccccccc}
\hline $\begin{array}{l}\text { rs256733 } \\
(-5429 \mathrm{~T} / \mathrm{G})\end{array}$ & $\begin{array}{c}\text { rs2739448 } \\
(-5412 \mathrm{~T} / \mathrm{C})\end{array}$ & $\begin{array}{c}\text { rs925013 } \\
(-4643 \mathrm{~A} / \mathrm{G})\end{array}$ & $\begin{array}{c}\text { Total } \\
(\%)\end{array}$ & $\begin{array}{c}\text { Controls } \\
(\%)\end{array}$ & $\begin{array}{c}\text { Cases } \\
(\%)\end{array}$ & OR $(95 \% \mathrm{CI})^{\mathrm{a}}$ & $\begin{array}{r}\text { P-value } \\
\mathrm{T}\end{array}$ \\
$\mathrm{T}$ & $\mathrm{T}$ & $\mathrm{A}$ & 83 & 84 & 82 & 1.00 & - \\
$\mathrm{T}$ & $\mathrm{C}$ & $\mathrm{G}$ & 12 & 13 & 11 & $1.07(0.54-2.12)$ & 0.84 \\
$\mathrm{~T}$ & $\mathrm{~T}$ & $\mathrm{G}$ & 2.3 & 1.4 & 3.7 & $0.36(0.09-1.55)$ & 0.17 \\
$\mathrm{G}$ & $\mathrm{C}$ & $\mathrm{A}$ & 1.3 & 0.4 & 2.4 & $0.18(0.02-1.73)$ & 0.14 \\
\hline
\end{tabular}

${ }^{\mathrm{a} A g e-a d j u s t e d ~ o d d s ~ r a t i o . ~ G l o b a l ~ P-v a l u e ~ f o r ~ m o d e l ~}<0.27$.

Table VII. Association between PSA haplotypes and the occurrence of advanced prostate cancer.

\begin{tabular}{lccccccc}
\hline $\mathrm{rs} 256733$ & $\mathrm{rs} 2739448$ & $\mathrm{rs} 925013$ & Total \\
$(-5429 \mathrm{~T} / \mathrm{G})$ & $(-5412 \mathrm{~T} / \mathrm{C})$ & $(-4643 \mathrm{~A} / \mathrm{G})$ & $(\%)$ & $\begin{array}{c}\text { Advanced } \\
(\%)\end{array}$ & $\begin{array}{c}\text { Localized } \\
(\%)\end{array}$ & OR (95\% CI $)^{\mathrm{a}}$ & P-value \\
\hline $\mathrm{T}$ & $\mathrm{T}$ & $\mathrm{A}$ & 82 & 76 & 88 & 1.00 & \\
$\mathrm{G}$ & $\mathrm{C}$ & $\mathrm{G}$ & 11 & 15 & 6.7 & $3.51(1.02-12.11)$ & 0.051 \\
$\mathrm{~T}$ & $\mathrm{~T}$ & $\mathrm{G}$ & 4.2 & 4.3 & 4.1 & $1.62(0.29-9.14)$ & 0.58 \\
$\mathrm{G}$ & $\mathrm{C}$ & $\mathrm{A}$ & 2.1 & 2.9 & 1.4 & $3.77(0.3-47.6)$ & 0.31 \\
\hline
\end{tabular}

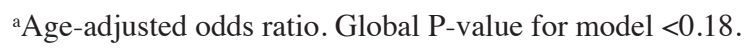

Table VIII. Association between serum PSA levels in prostate cancer patients and controls.

\begin{tabular}{lccccc}
\hline SNP & Variants & Controls $(\mathrm{n}=109)$ & P-value & Patients (n=84) & P-value \\
\hline rs256733 & TT & $0.13 \pm 0.18$ & 0.7 & $1.52 \pm 0.87$ & 0.4 \\
& TG & $0.15 \pm 0.18$ & & $1.69 \pm 0.59$ & \\
rs2739448 & TT & $0.13 \pm 0.18$ & 0.7 & $1.51 \pm 0.87$ & 0.29 \\
& TC & $0.15 \pm 0.18$ & & $1.72 \pm 0.58$ & 0.38 \\
rs925013 & AA & $0.13 \pm 0.18$ & 0.54 & $1.52 \pm 0.87$ & \\
& AG & $0.15 \pm 0.18$ & & $1.69 \pm 0.62$ & \\
\hline
\end{tabular}

Mean log base -10 (log 10) transformed serum PSA levels.

observed between the genotypes of each SNP. However, a trend towards increased serum PSA levels in males carrying heterozygous PSA genotypes in each SNP was observed.

\section{Discussion}

The identification of men at high risk of advanced prostate cancer is of great importance for diagnosis, prognosis and the determination of treatment modalities for the disease. The isolation of patients predisposed to the advanced condition is therefore essential. In the present study, we aimed to examine variants of the PSA gene and their ability to predict the risk of prostate cancer and the occurrence of advanced prostate cancer, as well as their association with serum PSA levels, in an Indian population.

The heterozygous genotype in the enhancer region of the PSA gene showed a strong association with the occurrence of advanced prostate cancer. However, these polymorphisms failed to show a statistically significant association with the risk for prostate cancer when compared with the control group. The heterozygous $\mathrm{G}$ allele at rs2569733, C allele at rs2739448 and $G$ allele at rs925013 showed 3.6-, 3.2- and 2.4-fold increases, respectively, in the risk of developing advanced prostate cancer. A prevalence of the heterozygous genotype in all three SNPs was observed in $27-30 \%$ of men in the control and prostate cancer groups. Strong linkage disequlibrium was observed for all three SNPs. The haplotype $\mathrm{G} / \mathrm{C} / \mathrm{G}$ for rs2569733/rs2739448/rs925013 showed a frequency of $11 \%$ and a 3.5-fold increased risk of the development of advanced prostate cancer. To our knowledge, this is the first study to report the influence of the PSA genotype in the enhancer region on the occurrence of advanced prostate cancer.

To date, only two studies have examined polymorphisms in the enhancer region of the PSA gene and their possible 
association with serum PSA levels and the risk of prostate cancer $(22,23)$. Cramer et al were the first to identify polymorphisms in the 5 ' promoter region of the PSA gene and to analyze their association with serum PSA levels (22). The three variants reported in their Caucasian population were: $\mathrm{G}$ allele at rs2569733, $\mathrm{C}$ allele at rs2739448 and $\mathrm{G}$ allele at rs 925013 , with frequencies of 23,22 and $21.2 \%$, respectively. The authors also reported a genotype frequency of almost $33 \%$ for each of the SNPs and a strong association with increased serum PSA levels. All three SNPs were also reported to be in strong linkage disequilibrium. The haplotype $-5429 \mathrm{G} /-5412$ C/-4643 G was shown to occur in $20 \%$ of the population and was found to be associated with increased serum PSA levels. By contrast, a study by Beebe-Dimmer et al (23) in African Americans reported a heterozygous genotype and haplotype frequency of $18-19 \%$ and $9 \%$, respectively, with no significant association between serum PSA levels and prostate cancer risk. In our study population, the heterozygous genotype frequency observed (27-30\%) was similar to that of Caucasian males (33\%) as reported by Cramer et al, while the haplotype frequency was similar to that of African Americans (9\%) as reported by Beebe-Dimmer et al. We did not observe the minor homozygous genotype noted by Cramer et al in a substantial proportion of the Caucasian population (4-7\%); however, this was in agreement with the findings of Beebe-Dimmer et al, who observed only one case $(0.3 \%)$ with the minor homozygous genotype in African Americans. These findings clearly indicate an ethnic disparity, which may influence the progression of prostate cancer in South Asian populations.

We did not observe a statistically significant difference in the serum PSA levels of prostate cancer patients or controls with the heterozygous genotype compared to those with the homozygous genotype. The expression of PSA is not exclusively controlled by the enhancer region; functional SNPs present in the proximal promoter region may also exert an effect on expression levels. It is likely that the functional polymorphisms in the two regions influence PSA expression independently or counterbalance the effect of the other depending on their linkage status. A recent study by Savblom et al (24) reported moderate linkage disequilibrium between the $-4643 \mathrm{~A} / \mathrm{G}$ and $-158 \mathrm{G} / \mathrm{A}$ polymorphisms in the proximal promoter region of the PSA gene, indicating its independent influence on PSA expression levels.

The biological impact of polymorphisms in the PSA gene on the progression of prostate cancer has yet to be revealed. PSA is indirectly involved in prostate epithelial cell proliferation owing to its proteolytic activity on IGFBP-3 (25). On the other hand, PSA has been reported to be antiangiogenic (26). Recent studies on the effect of PSA as a mitogen in the induction of osteoblastic differentiation revealed that PSA produced by prostate cancer cells may participate in bone remodeling in favor of osteoblastic activity in metastasis (27). Therefore, genetic variations in the PSA gene, which in turn regulate its expression and thus PSA levels, may be linked to the process of metastasis in prostate cancer.

Our findings indicate that polymorphisms of the PSA gene may not qualify as independent risk factors for prostate cancer, but may modulate its progression. The time lag between progression from localized prostate cancer to the stage of metastasis is a key factor that shows individual variation and hence predicts treatment options. Consequently, the identifica- tion of men at considerable risk of advanced prostate cancer according to their PSA genotype may aid in the determination of the appropriate treatment regimen.

Though the sample size of our population was small due to the low incidence rate of prostate cancer among Indian men, the correlation between heterozygosity in the enhancer region of the PSA gene and the occurrence of advanced prostate cancer is a unique and noteworthy finding. Further studies with larger sample size are required to confirm the implications of this observation. We highly recommend systematic screening of the PSA gene for detection of its functional genetic variants, as this may aid in determining the role of PSA in modulating the progression of prostate cancer.

In conclusion, the study of these polymorphisms in patients with prostate cancer may determine their predisposition to development of advanced prostate cancer, thus enabling improvements in therapeutic strategies so as to arrest progression to widespread metastasis.

\section{Acknowledgements}

Grant support from (1) the Board of Research in Nuclear Science, Department of Atomic Energy (2007/37/65/BRNS), Government of India and (2) the Indian Council of Medical Research, India (3/2/2/135/2007/NCD-III).

\section{References}

1. Jemal A, Siegel R, Ward E, Hao Y, Xu J and Thun MJ: Cancer Statistics, 2009. CA Cancer J Clin 59: 225-249, 2009.

2. Chu KC, Tarone RE and Freeman HP: Trends in prostate cancer mortality among black men and white men in the United States. Cancer 97: 1507-1516, 2003.

3. Hebert JR, Ghumare SS and Gupta PC: Stage at diagnosis and relative differences in breast and prostate cancer incidence in India: comparison with the United States. Asian Pac J Cancer Prev 7: 547-555, 2006.

4. Drago JR, Badalament RA, Weintjes MG, et al: Relative value of prostate specific antigen and prostatic acid phosphatase in diagnosis and management of adenocarcinoma of prostate. Ohio State University experience. Urology 34: 187-193, 1989.

5. Chavan PR, Chavan SV, Chavan NR and Trivedi VD: Detection rate of prostate cancer using prostate specific antigen in patients presenting with lower urinary tract symptoms: a retrospective study. J Postgrad Med 55: 17-21, 2009.

6. Leibovici D, Spiess PE, Agarwal PK, Tu SM, Pettaway CA, Hitzhusen K, Millikan RE and Pisters LL: Prostate cancer progression in the presence of undetectable or low serum prostate-specific antigen level. Cancer 15: 198-204, 2007.

7. Cleutjens KB, van Eekelen CC, van der Korput HA Brinkmann AO and Trapman J: Two androgen response regions cooperate in steroid hormone regulatory activity of the prostate specific antigen promoter. J Biol Chem 271: 6379-6388, 1996.

8. Cleutjens KB, van der Korput HA, van Eekelen CC, van Rooij HC, Faber PW Brinkmann AO and Trapman J: An androgen response element in a far upstream enhancer region is essential for high, androgen-regulated activity of the prostate specific antigen promoter. Mol Endocrinol 11: 148-161, 1997.

9. Xue W, Irvine RA, Yu MC, Ross RK, Coetzee GA and Ingles SA: Susceptibility to prostate cancer: interaction between genotypes at the androgen receptor and prostate-specific antigen loci. Cancer Res 60: 839-841, 2000.

10. Xue WM, Coetzee GA, Ross RK, Irvine R, Kolonel L, Henderson BE and Ingles SA: Genetic determinants of serum prostate-specific antigen levels in healthy men from a multiethnic cohort. Cancer Epidemiol Biomarkers Prev 10: 575-579, 2001.

11. Xu J, Meyers DA, Sterling DA, Zheng SL, Catalona WJ, Cramer SD, Bleecker ER and Ohar J: Association studies of serum prostate-specific antigen levels and the genetic polymorphisms at the androgen receptor and prostate-specific antigen genes. Cancer Epidemiol Biomarkers Prev 11: 664-669, 2002. 
12. Medeiros R, Morais A, Vasconcelos A, Costa S, Pinto D, Oliveira J, Carvalho R and Lopes C: Linkage between polymorphisms in the prostate specific antigen ARE1 gene region, prostate cancer risk, and circulating tumor cells. Prostate 53: 88-94, 2002.

13. Wang LZ, Sato K, Tsuchiya N, Yu JG, Ohyama C, Satoh S, Habuchi T, Ogawa $\mathrm{O}$ and Kato T: Polymorphisms in prostatespecific antigen (PSA) gene, risk of prostate cancer, and serum PSA levels in Japanese population. Cancer Lett 202: 53-59, 2003.

14. Rao A, Chang BL, Hawkins G, Hu JJ, Rosser CJ, Hall MC, Meyers DA, Xu J and Cramer SD: Analysis of G/A polymorphism in the androgen response element I of the PSA gene and its interactions with the androgen receptor polymorphisms. Urology 61: 864-869, 2003

15. Chiang $\mathrm{CH}$, Chen KK, Chang LS and Hong CJ: The impact of polymorphism on prostate specific antigen gene on the risk, tumor volume and pathological stage of prostate cancer. J Urol 171: $1529-1532,2004$.

16. Cicek MS, Liu X, Casey G and Witte JS: Role of androgen metabolism genes CYP1B1, PSA/KLK3, and CYP11alpha in prostate cancer risk and aggressiveness. Cancer Epidemiol Biomarkers Prev 14: 2173-2177, 2005.

17. Salinas CA, Austin MA, Ostrander EO and Stanford JL: Polymorphisms in the androgen receptor and the prostatespecific antigen genes and prostate cancer risk. Prostate 65: $58-65,2005$.

18. Severi G, Hayes VM, Neufing P, Padilla EJ, Tilley WD, Eggleton SA, Morris HA, English DR, Southey MC, Hopper JL, Sutherland RL, Boyle P and Giles GG: Variants in the prostatespecific antigen (PSA) gene and prostate cancer risk, survival, and circulating PSA. Cancer Epidemiol Biomarkers Prev 15: 1142-1147, 2006.

19. Sieh W, Edwards KL, Fitzpatrick AL, Srinouanprachanh SL, Farin FM, Monks SA, Kronmal RA and Eaton DL: Genetic susceptibility to prostate cancer: prostate-specific antigen and its interaction with the androgen receptor (United States). Cancer Causes Control 17: 187-197, 2006.
20. Lai J, Kedda MA, Hinze K, Smith RL, Yaxley J, Spurdle AB, Morris CP, Harris J and Clements JA: PSA/KLK3 AREI promoter polymorphism alters androgen receptor binding and is associated with prostate cancer susceptibility. Carcinogenesis 28: 1032-1039, 2007.

21. Jesser C, Mucci L, Farmer D, Moon C, Li H, Gaziano JM, Stampfer M, Ma J and Kantoff P: Effects of G/A polymorphism, rs266882, in the androgen response element I of the PSA gene on prostate cancer risk, survival and circulating PSA levels. Br J Cancer 99: 1743-1747, 2008.

22. Cramer SD, Chang BL, Rao A, et al: Association between genetic polymorphisms in the prostate specific antigen gene promoter and serum prostate specific antigen levels. J Nat Cancer Institute 95: 1044-1053, 2003.

23. Beebe-Dimmer JL, Lange LA, Cain JE, et al: Polymorphisms in the prostate-specific antigen gene promoter do not predict serum prostate-specific antigen levels in African-American men. Prostate Cancer Prostatic Dis 9: 50-55, 2006.

24. Savblom C, Giwercman A, Malm J, Hallden C, Lundin K, Lilja $\mathrm{H}$ and Giwercman Y: Association between polyorphisms in the prostate specific antigen (PSA) promoter and release of PSA. Int J Andrology 32: 479-485, 2009.

25. Cohen P, Peehl DM, Graves HC and Rosenfeld RG: Biological effects of prostate specific antigen as an insulin-like growth factor binding protein-3 protease. J Endocrinol 142: 407-415, 1994.

26. Fortier AH, Nelson BJ, Grella DK and Holaday JW: Antiangiogenic activity of prostate-specific antigen. J Natl Cancer Inst 91: 1635-1640, 1999.

27. Nadiminty N, Lou W, Lee SO, et al: Prostate-specific antigen modulates genes involved in bone remodelling and induces osteoblast differentiation of human osteosarcoma cell line SaOS-2. Clin Cancer Res 12: 1420-1430, 2006. 